\title{
Beliefs, attitude and knowledge of contact lens wear and care among Saudi Arabia population
}

\author{
Abdulrahman Jazaa Alharbi1* and Jehan Fouad Abdullah Sarriyah2 \\ ${ }^{1}$ Doctor of optometry (OD), Qassim University, Saudi Arabia \\ ${ }^{2}$ Medical student, Taif University, Saudi Arabia
}

\begin{abstract}
People wear contact lenses (CL) not only to correct the refractive errors of the eye, but also for cosmetic reasons. However, people who wear CL have little or no knowledge of the rules of proper handling of CL and of the complications they may cause. Our aim is to assess the awareness of CL wear and care in Saudi Arabia. This is a prospective cross-sectional study. A validated questionnaire was administered between June to July 2018. The age range of target participants was between 18 and 60 years. The invitation to participate in the study was sent to 900 individuals and the data was statistically analyzed using SPSS v24.01. The study targeted 507 participants, with a mean age $25.03 \mathrm{SD}( \pm 7.79)$. The results indicate that 100 participants $(29.5 \%)$ wear CL for refractive correction, $134(39.5 \%)$ wear them for cosmetic reasons, while 105 (31\%) wear them for both correction and cosmetic ends. Moreover, 498 (98\%) of the participants report that wearing contact lens during sleep is harmful to eyes, and $90 \%$ of the participants believed that swimming with CL might have negative effects on the eyes. $67 \%$ of the participants believed the misuse of contact lenses may cause corneal ulcer, $67 \%$ of participants think the contact lenses cause blindness. The use of contact lenses in Saudi Arabia is mainly for cosmetic reasons. Accordingly, there is a need for health education program on how to use contact lenses for cosmetic reasons to minimize their risks.
\end{abstract}

\section{Introduction}

A population-based survey revealed that around 4.9 million people wear contact lenses in the US [1]. In the UK, the number of CL wearers has gone up from 1.6 million in 1992 to 3.5 million in 2014 then to 3.7 million in 2016 [2]. The numbers for CL wearers in Saudi Arabia are not clear as most studies have concentrated on CL complications rather than exploring the CLs prevalence or compliance among the Saudi Arabian community [3-6].

Contact lenses (CL) are optical devices worn on the eye. They are directly placed on the surface of the cornea so as not to block oxygen from getting through it [7]. Contact lenses are soaring in popularity among the younger generations. People wear contact lenses not only to correct the refractive errors of the eye, but also for cosmetic reasons [8]. They come in two types: soft and hard contact lenses [9]. However, people who wear CL have little or no knowledge of the rules of proper handling of CL and of the complications they may cause [10]. Such complications can vary from a simple feeling of discomfort to sightthreatening conditions, such as microbial keratitis. These complications are related to the level of compliance with CL wear and care. The most common reasons for the low level of compliance, insufficient CL care education by eye care practitioners (ECPs), poor self-hygiene habits, missing aftercare visits and obtaining CLs from unauthorized vendors. [11-17]. Several studies have been carried out on the complications caused by CL and the most reported ones are eye dryness, corneal abrasion and edema, neovascularization giant papillary conjunctivitis, corneal ulcer and keratitis [18]. The aim of this study is to assess the awareness of CL wear and care in Saudi Arabia. Materials and methods

This is a prospective cross-sectional study. A validated questionnaire was administered between June to July 2018. A random cluster sampling method was applied to select participants in Saudi Arabia. A well-structured questionnaire was designed in Arabic and was electronically administered. In addition, a paper-based survey was used to collect responses from illiterate participants and those who do not use smartphones. Their responses were later processed electronically. The questionnaire aimed at collecting data related to the demographics of the participant, their knowledge, attitude, practice of contact lens wear and daily care, awareness toward common complications and how to handle them. The age range of target participants was between 18 and 60. The invitation to participate in the study was sent to 900 individuals. The data was exported from google sheets to Microsoft Excel for the descriptive analysis. Using SPSS v24.0 to investigate the association of independent variables (age, gender, educational level, history of eye exam) with the dependent variables (knowledge, belief and attitude on contact lens). The $\mathrm{p}$ value for the test significance was set at 0.05 .

\section{Results}

This study included 507 participants with a response rate of $56.5 \%$. Their ages ranged from 10 to 80 years with a mean \pm SD of age 25.03 ( \pm 7.79 years) $77.7 \%$ of the participants were females and $23.3 \%$ were males. The participants' level of education ranged from illiteracy to postgraduate studies, from maximum to minimum 272 (53.6\%) bachelor degree, 196 (38.7\%) school education, 38 (7.5\%) post-graduate studies, $1(0.2 \%)$ illiterate. The geographical distribution of the participants was as follows: $354(69.8 \%)$ from the western region, $83(16,4 \%)$ from the central region, $26(5.1 \%)$ from the eastern region, $26(5.1 \%)$ from

${ }^{\star}$ Correspondence to: Abdulrahman Jazaa Alharbi, Doctor of optometry (OD), Qassim University, Saudi Arabia, E-mail: Abdulrhman426@hotmail.com

Key words: contact lens, Saudi Arabia, awareness, retractive errors

Received: August 12, 2019; Accepted: August 20, 2019; Published: August 23, 2019 
the south and 18 (3.6\%) from the north. 243 (47.9\%) of participants reported having undergone an eye examination in the past year, 116 (22.9\%) had an eye examination within 5 years, 59 (11.6) had an eye examination more than 5 years ago and 89 (17.6) reported that they had never had an eye examination (Table 1). Three hundred and thirtynine (67.8\%) of participants were using contact lens in which 303 were females and 36 were males. The purpose of wearing contact lens was $100(29.5 \%)$ for refractive correction, $134(39.5 \%)$ were cosmetic while $105(31 \%)$ for correction \& cosmetic. 498 (98\%) of the participants were aware that wearing contact lenses during sleep is harmful. 332 out of the 498 use contact lenses, while the remaining 166 don't use them.

The majority of participants, 373 (74\%) believed that handling contact lens before makeup is better in which 271 use contact lens and 102 don't use them. The rest of participants believed that the use contact lens after makeup is better. The American Optometric Association recommends replace the contact lens case at least every three months. $74(15 \%)$ of participants reported that they should replace the lens storage case at least once every year, $166(33 \%)$ of the participants reported that they should replace the lens storage case at least once every 6 months, $146(26 \%)$ of the participants show that they should replace lens storage case monthly, $19(4 \%)$ of the participants reported that they should replace the lens storage case every two weeks, 34 (7\%) of the participants reported that they should replace the lens storage case weekly, 68 (13\%) of the participants think that they should replace lens storage case daily. Among the contact lenses wearers 175 (52\%) purchase their contact lens without a prescription from a specialist. Furthermore, 206 (15\%), 22 (6\%) and 15 (5\%) purchase their contact lens from optical shop, pharmacy and beauty salons, respectively. Ninety percent of the participants believe swimming with contact lens might have negative effects on the eyes. $67 \%$ of the participants believed the misuse of contact lenses may cause corneal ulcer while $33 \%$ did not believe that. $67 \%$ of participants think the contact lenses cause blindness and 33\% did not think that (Table 2).

\section{Discussion}

The results of the study suggest that women prefer to use contact lenses for medical purposes as a substitute for the glasses. The lenses give them more flexibility, freedom, a more beautiful appearance and perhaps for aesthetic purposes to change the color of your eyes and brighten your eyes [7].

Three hundred and thirty-nine (67.8\%) of participants were using contact lens in which 303 were females and 36 were males. The purpose of wearing contact lens was 100 (29.5\%) for refractive correction, 134 (39.5\%) were cosmetic while 105 (31\%) for correction \& cosmetic. 67\% of participants believed the misuse of contact lenses may cause corneal ulcer while $33 \%$ did not believed that. $\% 67$ of participants think the contact lenses cause blindness and 33\% did not think that. $67 \%$ of the participants believed the misuse of contact lenses may cause corneal ulcer while $33 \%$ did not believe that. $67 \%$ of participants think the contact lenses cause blindness and 33\% did not think that.

A cross sectional descriptive study was carried out between 1st August 2012 to 30th November 2012 in Fatima Memorial Hospital College of Medicine and Dentistry to determine the awareness of contact lens care among medical students. This study revealed that medical student, even though they have good knowledge of the use of $\mathrm{CL}$, are not fully aware of the proper way to clean the CL and their cases. Failure to comply with the hygiene rules of CL can have serious repercussions on the eye. A good care system of $\mathrm{Cl}$ is likely to maximize comfort, improve eyesight, improve the health of the eye and keep the lenses hydrated. In this study revealed that women use CL to correct refractive errors, while in our study revealed that women in Saudi Arabia wear it mostly for cosmetic reasons [8].

Another cross-sectional study was carried out $\mathrm{n}$ Saudi Arabia between January-March 2013 in order to evaluate the use and knowledge of CL among women. The study aimed also at investigating the dispensation practices of CL in non-ophthalmic stores. The results of the study suggest that CL use is prevalent among Saudi women, particularly for cosmetic reasons. The findings of this study agree with this study in that the majority of CL users purchase them from optical shops [9].

Finally, in a cross-sectional descriptive study conducted in January 2013, researchers sough to discover the awareness level of the indications and care of CL among medical students. The study found out that the majority of medical students were unaware of the important indications of contact lens. Our study is similar in wearing CL during sleep is reported to be harmful by the participants [10].

Table 1. Demographic Profile of the Participants and their Eye Examination ( $n=507)$

\begin{tabular}{|c|c|c|c|}
\hline \multicolumn{2}{|l|}{ Variable } & $n$ & Percentage (\%) \\
\hline \multirow{4}{*}{ Age } & Minimum=10 years & \multirow{4}{*}{507} & \multirow{4}{*}{100} \\
\hline & Maximum $=80$ years & & \\
\hline & Mean $=25.03$ & & \\
\hline & Std. Deviation $= \pm 7.79$ & & \\
\hline \multirow{2}{*}{ Gender } & Male & 113 & 22.3 \\
\hline & Female & 394 & 77.7 \\
\hline \multirow{4}{*}{ Educational level } & Illiterate & 1 & 0.2 \\
\hline & School & 196 & 38.7 \\
\hline & Bachelor & 272 & 53.6 \\
\hline & Post graduate & 38 & 7.5 \\
\hline \multirow{5}{*}{ Region* } & Central & 83 & 16.4 \\
\hline & Northern & 18 & 3.6 \\
\hline & Southern & 26 & 5.1 \\
\hline & Western & 354 & 69.8 \\
\hline & Eastern & 26 & 5.1 \\
\hline \multirow{4}{*}{ Last eye examination } & More than 5 years & 59 & 11.6 \\
\hline & Less than 5 years & 116 & 22.9 \\
\hline & Less than 1 year & 243 & 47.9 \\
\hline & Never had an eye exam & 89 & 17.6 \\
\hline
\end{tabular}


Table 2. Distribution of the Knowledge of Contact Lens by Contact Lens Wearers $(n=507)$

\begin{tabular}{|c|c|c|c|c|}
\hline Variable & Category & Using CL (\%) & Not using CL (\%) & Total (\%) \\
\hline \multicolumn{5}{|c|}{ Purpose of wearing contact lens } \\
\hline & Correction & $100(29.5)$ & -- & $100(29.5)$ \\
\hline & Cosmetic & $134(39.5)$ & -- & $134(39.5)$ \\
\hline & Correction \& Cosmetic & $105(31)$ & -- & $105(31)$ \\
\hline & Total & $339(100)$ & -- & $339(100)$ \\
\hline \multicolumn{5}{|c|}{ Sleeping with contact lenses are harmful to the eyes } \\
\hline & Yes & $332(98)$ & $166(99)$ & $498(98)$ \\
\hline & No & $7(2)$ & $2(1)$ & $9(2)$ \\
\hline & Total & $339(100)$ & $168(100)$ & $507(100)$ \\
\hline \multicolumn{5}{|c|}{ Wearing contact lens before or after makeup } \\
\hline & Before & $271(80)$ & $102(61)$ & $373(74)$ \\
\hline & After & $68(20)$ & $66(39)$ & $134(26)$ \\
\hline & Total & $339(100)$ & $168(100)$ & $507(100)$ \\
\hline \multicolumn{5}{|c|}{ Replace contact lens cases } \\
\hline & Daily & $50(15)$ & $18(11)$ & $68(13)$ \\
\hline & Weekly & $11(3)$ & $23(14)$ & $34(7)$ \\
\hline & Every two weeks & $8(2)$ & $11(7)$ & $19(4)$ \\
\hline & Monthly & $87(26)$ & $59(35)$ & $146(29)$ \\
\hline & Every six months & $121(36)$ & $45(27)$ & $166(33)$ \\
\hline & Yearly & $62(18)$ & $12(6)$ & $74(15)$ \\
\hline & Total & $339(100)$ & $168(100)$ & $507(100)$ \\
\hline \multicolumn{5}{|c|}{ Purchase contact lenses based on prescription of specialist } \\
\hline & Yes & $164(48)$ & -- & $164(48)$ \\
\hline & No & $175(52)$ & -- & $175(52)$ \\
\hline & Total & $339(100)$ & -- & $339(100)$ \\
\hline \multicolumn{5}{|c|}{ Places to purchase contact lenses } \\
\hline & Optical shop & $206(15)$ & -- & $206(15)$ \\
\hline & Pharmacy & $22(6)$ & -- & $22(6)$ \\
\hline & Beauty salon & $15(5)$ & -- & $15(5)$ \\
\hline & Optical shop \& pharmacy & $85(25)$ & -- & $85(25)$ \\
\hline & Optical shop \& beauty salon & $3(1)$ & -- & $3(1)$ \\
\hline & Pharmacy \& beauty salon & $8(2)$ & -- & $8(2)$ \\
\hline & $\begin{array}{c}\text { Optical shop \& pharmacy \& } \\
\text { beauty salon }\end{array}$ & 0 & -- & 0 \\
\hline & Total & $339(100)$ & -- & 339 (100) \\
\hline \multicolumn{5}{|c|}{ Swimming with contact lenses are harmful to the eyes } \\
\hline & Yes & $308(91)$ & $150(89)$ & $458(90)$ \\
\hline & No & $31(9)$ & $18(11)$ & $49(10)$ \\
\hline & Total & $339(100)$ & $168(100)$ & $507(100)$ \\
\hline \multicolumn{5}{|c|}{ Misuse of contact lenses may cause corneal ulcer } \\
\hline & Yes & $216(64)$ & $124(74)$ & $340(67)$ \\
\hline & No & $123(36)$ & $44(26)$ & $167(33)$ \\
\hline & Total & $339(100)$ & $168(100)$ & $507(100)$ \\
\hline \multicolumn{5}{|c|}{ Complications of contact lens may lead to blindness } \\
\hline & Yes & $216(64)$ & $124(74)$ & $340(67)$ \\
\hline & No & $123(36)$ & $44(26)$ & $167(33)$ \\
\hline & Total & $339(100)$ & $168(100)$ & $507(100)$ \\
\hline
\end{tabular}

\section{Conclusion}

The use of contact lenses in Saudi Arabia is mainly for cosmetic reasons. Accordingly, there is a need for health education program on how to use contact lenses for cosmetic reasons to minimize their risks. These programs should aim at promoting CL hygiene practices and eliminating the likelihood of CL related complications.

\section{Acknowledgment}

The authors of this paper would like to express their sincere thanks to Professor Naganathan Muthuramalingam for his support and valuable feedback throughout the research. Special thanks are due also to all the participants who agreed to take part in the survey.

\section{Funding}

No fund or grants in this research.

\section{References}

1. Cope JR, Collier SA, Rao MM, Chalmers R, Mitchell GL, et al. (2015) Contact lens wearer demographics and risk behaviors for contact lens-related eye infections-United States, 2014. MMWR Morb Mortal Wkly Rep 64: 865-870.

2. ACLM (2017) Current News, The Association of Contact Lens Manufacturers.

3. Abdelkader A (2014) Cosmetic soft contact lens associated ulcerative keratitis in southern Saudi Arabia. Middle East Afr J Ophthalmol 21: 232-235.

4. Tabbara KF, El-Sheikh HF, Aabed B (2000) Extended wear contact lens related bacterial keratitis. Br J Ophthalmol 84: 327-328. 
5. Aldebasi YH, Aly SM, Ahmad MI, Khan AA (2013) Incidence and risk factors of bacteria causing infectious keratitis. Saudi Med J 34: 1156-1160.

6. Alfawaz A (2011) Radial keratoneuritis as a presenting sign in Acanthamoeba keratitis. Middle East Afr J Ophthalmol 18: 252-255.

7. Collins MJ, Carney LG (1986) Patient compliance and its influence on contact lens wearing problems. Am J Optom Physiol Opt 63: 952-956.

8. Tanisha I, Reddy SC, Phuah SJ (2008) Knowledge and practice of contact lens wear and care among Medical Students of University of Malaya. Med J Malaysia 63: 11211124

9. Stein HA, Freeman MI, Stein RM, Maund LD (1997) Contact Lenses Fundamentals and Clinical Use. Slack Incorporated 2: 59-74.

10. Qureshi MM, Khan B (2009) Awareness of contact lens care among medical students. Medical Channel 15: 85-88.

11. Bui TH, Cavanagh HD, Robertson DM (2010) Patient compliance during contact lens wear: perceptions, awareness, and behavior. Eye \& contact lens 36: 334-339.
12. Kuzman T, Kutija MB, Juri J, Jandroković S, Škegro I, et al. (2014) Lens wearers noncompliance-Is there an association with lens case contamination?. Cont Lens Anterior Eye e 37: 99-105.

13. Kuzman T, Barišić Kutija M, Masnec S, Jandroković S, Mrazovac D, et al. (2014) Compliance among soft contact lens wearers. Coll Antropol 38: 1217-1221.

14. Joslin CE, Tu EY, Shoff ME, Booton GC, Fuerst PA, et al. (2007) The association of contact lens solution use and Acanthamoeba keratitis. Am J Ophthalmol 144: 169-180.

15. Robertson DM, Cavanagh HD (2011) Non-compliance with contact lens wear and care practices: a comparative analysis. Optom Vis Sci 88: 1402-1408.

16. Loh K, Agarwal P (2010) Contact lens related corneal ulcer. Malays Fam Physician 5: 46.

17. Dart JK, Radford CF, Minassian D, Verma S, Stapleton F (2008) Risk factors for microbial keratitis with contemporary contact lenses: a case-control study. Ophthalmology 115: 1647-1654

18. Suchecki JK, Donshik P, Ehlers WH (2003) Contact lens complications. Ophthalmol Clin N Am 6: 471-484.

Copyright: (C2019 Alharbi AJ. This is an open-access article distributed under the terms of the Creative Commons Attribution License, which permits unrestricted use, distribution, and reproduction in any medium, provided the original author and source are credited. 